\author{
Milica D. Dinić Marinković* \\ Univerzitet u Beogradu \\ Filološki fakultet \\ Katedra za opštu lingvistiku
}

\title{
O FIGURATIVNOM JEZIKU U UDŽBENICIMA ISTORIJE ZA OSNOVNU ŠKOLU**
}

\author{
Originalni naučni rad \\ UDC 81'373:[37.016:94 \\ https://doi.org/10.18485/kkonline.2020.11.11.2
}

\begin{abstract}
Osnovni ciljevi ovoga rada jesu izdvajanje i predstavljanje dominantnih formi figurativnog jezika koje se javljaju u udžbenicima istorije za osnovnu školu, potom njihova tipologizacija, i, na kraju, analiza njihove varijabilnosti. Izdvojena su dva dominantna tipa figurativnog jezika u analiziranim udžbenicima - gramatička metafora i metonimijski prenosi. U analizi gramatičke metafore primenjen je tranzitivni metod sistemske funkcionalne lingvsitike, dok su obrasci metonimijskih prenosa izdvojeni na osnovu izvornih entiteta koji su u analiziranim udžbenicima iskazani etnonimima, antroponimima i toponimima, kao i jedinicama opšteg leksikona koje označavaju lokaciju, državne institucije, društvene funkcije i titule. Ustanovljeno je da gramatički metaforične reprezentacije značenja formiraju postvaren diskurs, u kome događaji postaju stvari, a učesnici u događaju najčešće bivaju svedeni na okolnosti. Analiza varijabilnosti tipova figurativnog jezika pokazuje da je upotreba određenog tipa figure tematski zavisna, a ne, ili bar ne isključivo, osobina žanra, kao i da što smo na vremenskoj osi bliže našoj poziciji, to se sve manje ukazuje na odgovornost pojedinačnih aktera. Budući da je figurativni jezik i diskurzivno sredstvo kojim se kod adresata postiže željena reprezentacija određenog referenta ili događaja, rad pokreće i pitanje o tome kakva se slika sveta kod učenika formira reprezentovanjem istorijskih događaja i procesa na način na koji se to u analiziranim udžbenicima čini.
\end{abstract}

Ključne reči: jezik udžbenika, udžbenici istorije, figurativni jezik, gramatička metafora, obrasci metonimijskih prenosa.

\section{Uvod}

Predmet ovoga rada jeste figurativni jezik u udžbenicima istorije za drugi ciklus obaveznog obrazovanja u R. Srbiji. Terminom figurativni jezik označava se koncept koji nije homogen i strogo definisan. Pod njim se podrazumevaju sve jezičke realizacije kojima su u doslovnoj interpretaciji narušeni istinosni uslovi, i primarno se odnosi na metaforičke i metonimijske prenose, ali su njime obuhvaćene i druge figure - ironija,

\footnotetext{
* Katedra za opštu lingvistiku, Filološki fakultet Univerziteta u Beogradu, Studentski trg 3, 11000 Beograd, Srbija; e-mail: milica.dinic.marinkovic@fil.bg.ac.rs

** Ovaj rad prethodno je izložen na skupu "Primenjena lingvistika danas - Nove tendencije u teoriji i praksi" (Novi Sad, Filozofski fakultet, 27-29.11.2015).
} 
hiperbola, eufemizmi, idiomi i sl. (Gibbs, 1994; Katz et al., 1998; Stern, 2006; Deignan et al., 2013).

Početak obrazovnog procesa određen je susretom sa novim i posebnim pojavnim oblikom jezika - pisanim jezikom. Pisani jezik ne predstavlja puko zapisivanje usmenog jezika, već je reč o posebnom mediju, jeziku koji se i po svom sadržaju, a ne samo po fizičkom obliku, značajno razlikuje od usmenog. On je dekontekstualizovan u odnosu na neposredno iskustvo, mnogo eksplicitniji i znatno leksički raznovrsniji i apstraktniji. Ovaj jezik naziva se i obrazovnim jezikom ili jezikom škole (eng. educational language) i stoji nasuprot terminu zdravorazumski jezik (eng. common sense language), odnosno nasuprot svakodnevnom usmenom jeziku kome smo pre otpočinjanja obrazovnog procesa dominantno izloženi (up. Halliday, 1993 i 2016).

Tipičan oblik pisanog jezika koji dominira u školskom diskursu jeste jezik udžbenka. Jezik udžbenika je „specifičan, formalan, u određenom vidu ritualizovan i krajnje konzervativan jezik" (Plut, 2003: 207)³. Specifičnost jezika udžbenika ogleda se u većoj leksičkoj gustinit u odnosu na usmeni jezik, u visokom prisustvu leksike specijalizovanog domena, ali i u upotrebi specifičnog figuratvnog jezika. Martin ističe da se, počevši od drugog ciklusa obaveznog obrazovanja ${ }^{5}$, kada se u nastavni program uvodi veći broj naučnih disciplina, a samim tim i udžbenika namenjenih njihovom savladavanju, pred učenike postavlja zahtev da ovladaju jednom posve novom jezičkom formom "visoko specijalizovanog diskursa pojedinačnih nastavnih predmeta koji obiluje gramatički metaforičnim reprezentacijama značenja" (Martin, 2013: 23) ${ }^{6}$. Tako, suprotno uvreženom mišljenju da je jezik udžbenika suvoparan, što posebno važi za udžbenike istorije (,samo datumi i imena"), ispostavlja se da je figurativni jezik opšta karakteristika udžbeničkog žanra (up. Martin, 2013; Halliday, 1989; Halliday i Martin, 1993; Temmerman, 2000; Deignan et al., 2013).

Kao osnovno pisano sredstvo podučavanja, udžbenik je i sredstvo kulturnoposredovanog razvoja. Naime, udžbenik kao kulturno-potporni sistem (Plut, 2003) direktno utiče kako na jezički i kognitivni razvoj, tako i na formiranje i razvoj pismenosti, ali i na formiranje slike o svetu u kome živimo. U svojim prvobitnim

\footnotetext{
3 Jedno istraživanje s kraja 20. veka pokazuje da je jezik udžbenika u Australiji u periodu od 100 godina ostao gotovo nepromenjen (Lynch i Strube, 1983 preko Groves, 1995: 233).

4 Termin leksička gustina odnosi se na (procentualnu) zastupljenost punoznačnih reči u određenom jezičkom uzroku (Halliday, 1989: 62 i Johansson, 2008: 65-67)

5 Preciznije, Martin navodi "secondary school education", koje u sistemu obaveznog obrazovanja Australije počinje od 7. ili 8. godine obaveznog školovanja (v.https://www.studyinaustralia.gov.au/english/australianeducation/education-system), što odgovara drugom ciklusu obaveznog obrazovanja u R. Srbiji, koje počinje od 5. razreda.

${ }^{6}$ O gramatičkoj metafori v. tačku 3.1. ovog rada.
} 
formama udžbenici su primarno sagledavani "kao nosioci javnog morala i kanonizovano sredstvo za inicijaciju u društvo" (Luke, 1997), ali ni danas nisu knjige namenjene isključivo podučavanju i razvoju kompetencija učenika. Udžbenici ne samo da pretenduju „da budu kulturni modeli, mali uzorci u kojima je sadržano sve (ili gotovo sve) što je bitno za jednu kulturu" (Plut, 2003: 45), već i izborom tema, načinom njihovog predstavljanja, kao i izborom jezičkih sredstava kojima će izabrana znanja o svetu biti reprezentovana, više ili manje eksplicitno, ali bez sumnje direktno, utiču na formiranje predstave o svetu i stavova kod svojih korisnika.

Tako, budući da se "saznavanje" može poimati „kao intertekstualni proces" (Temmerman, 2000: 1-38, 219-229), kao i da je "znanje neodvojivo od značenja" (Martin, ibid.), ispitivanje figurativnog jezika u udžbenicima ima dvostruko uporište. Prvo, izdvajanje dominantnih formi figurativnog jezika u udžbenicima pokazuje kojim formama figurativnog jezika je neophodno da učenici ovladaju u cilju razumevanja teksta i savladavanja gradiva. Drugo, opis diskursa koji fomira određeni figurativni jezik pokazuje nam kakvu predstavu o svetu konstruiše određeni udžbenik, a udžbenici istorije, možda više no bilo koji drugi, pretenduju na saobražavanje svetonazora svojih korisnika. Analiza izbora jezičkih sredstava kojima je određeno znanje o svetu predstavljeno u udžbeniku višestruko je opravdana, jer, pored toga što su metaforički i metonimijski prenosi odraz univerzalnih jezičkih (neki bi rekli i saznajnih) procesa, oni se upotrebljavaju i „namerno, sa ciljem da se promeni perspektiva adresata o referentu ili temi koja je predmet prenosa, odnosno da se postigne da adresat na stvari gleda iz drugog konceptualnog domena, koji sada funkcioniše kao izvorni" (Steen, 2008: 222).

Kada je reč o upotrebi figurativnog jezika u udžbenicima, otvoreno je pitanje da li je figurativni jezik isključivo odlika udžbeničkog žanra, ili je (delom i) rezultat namere autora da se kod adresata postigne željeni pogled na stvari. Za razrešenje ove dileme od suštinskog je značaja utvrditi da li je upotreba određenog tipa figure u udžbenicima varijabilna. Tako, ukoliko izdvojeni obrasci ne variraju u odnosu na temu koju obrađuju, onda figurativni jezik jeste samo osobina žanra. Međutim, ukoliko upotreba izdvojenih figura varira u zavisnosti od teme, onda to znači da, pored inherentne osobine žanra, predstavlja i diskurzivno sredstvo za postizanje željene reprezentacije određenog referenta, odnosno teme.

Stoga su osnovni ciljevi ovoga rada: 1) izdvajanje dominantnih formi figurativnog jezika u udžbenicima istorije za osnovnu školu, 2) njihova tipologizacija i 3) ispitivanje 
varijabilnosti u upotrebi figurativnog jezika i njena uslovljenost temama koje se u analiziranim udžbenicima obrađuju.

\section{Korpus}

Korpus za istraživanje činile su izabrane teme iz udžbenika istorije za 5, 6. i 8. razred osnovne škole ${ }^{7}$. Usled prostornih ograničenja nije bilo moguće analizirati figurativni jezik u celokupnom korpusu udžbenika istorije za osnovnu školu. Stoga je konstruisan reprezentativni uzorak koji čini ukupno šest nastavnih tema. Izdvojene su po dve teme iz svakog pojedinačnog udžbenika, i to tako da jedna nastavna tema pripada opštoj, a druga nacionalnoj istoriji ${ }^{8}$. Ovaj princip narušen je jedino u udžbeniku za peti razred (I5), u kome se obrađuje period starog veka, te stoga u njemu nema nastavnih jedinica koje se odnose na teme iz nacionalne istorije. Zato je iz ovog udžbenika kao reprezentativni uzorak izdvojena jedna nastavna tema u kojoj se obrađuje predistorijsko doba, i jedna koja se odnosi na istoriju starog sveta.

Iz udžbenika I5 izdvojene su nastavna tema 2 - Praistorija i nastavna tema 6 Stari Rim.

Iz udžbenika I6 izdvojene su nastavna tema 4 - Evropa u poznom srednjem veku i tema 6 - Srpske zemlje i njihovo okruženje u doba osmanlijskih osvajanja.

Iz udžbenika I8 izdvojene su tema 3 - Prvi svetski rat (1914-1918) i tema 4 Srbija u velikom ratu.

Ovakav odabir tema pruža valjanu osnovu za ispitivanje varijabilnosti upotrebe različitih tipova figurativnog jezika u udžbenicima istorije za više razrede osnovne škole. Podaci o veličini obrađenog uzorka predstavljeni su u Tabeli 1.

Tabela 1: Kvantitativni podaci o obrađenoj građi

\begin{tabular}{|c|c|c|c|c|c|c|}
\hline Obrađeni uzorak & $\begin{array}{c}\text { I5 } \\
\text { Tema } 2 \\
\end{array}$ & $\begin{array}{c}\text { I5 } \\
\text { Tema } 6 \\
\end{array}$ & $\begin{array}{c}\text { I6 } \\
\text { Tema } 4 \\
\end{array}$ & $\begin{array}{c}\text { I6 } \\
\text { Tema } 6 \\
\end{array}$ & $\begin{array}{c}\text { I8 } \\
\text { Tema } 3 \\
\end{array}$ & $\begin{array}{c}\text { I8 } \\
\text { Tema } 4 \\
\end{array}$ \\
\hline $\begin{array}{c}\text { Veličina uzorka izražena } \\
\text { br. pojavnica }\end{array}$ & 1300 & 4428 & 4629 & 3513 & 1919 & 4482 \\
\hline Ukupan br. pojavnica & \multicolumn{6}{|c|}{20273} \\
\hline
\end{tabular}

\footnotetext{
7 U daljem tekstu ovi udžbenici označavaju se kao I5, I6 i I8. Poslednja cifra odnosi se na razred kome je udžbenik namenjen. Podaci o korišćenim udžbenicima, tj. izvorima, dati su na kraju rada u odeljku Izvori. ${ }^{8}$ Udžbenik za 7. razred nije uvršten u uzorak za analizu budući da teme iz nacionalne istorije koje ovaj udžbenik obrađuje čine veću celinu sa izabranom temom iz udžbenika za 6 . razred, te smo smatrali da bi time bila narušena reprezentatvnost uzorka potrebna za analizu varijabilnosti upotrebe različitih tipova figurativnog jezika.
} 


\section{Metode istraživanja}

Diskurs udžbenika dugogodišnji je predmet istraživanja u okviru Sidnejske škole funkcionalne lingvistike ( v, npr: Halliday, 1989, 1993; Halliday i Martin, 1993; Wignell, Martin i Eggins, 1989; Martin i Wodak, 2003; Martin, 2009 i 2013; Coffin, 1997, 2003 i 2006). Na temelju sistemske funkcionalne lingvistike M. A. K. Halideja i koncepta gramatičke metafore (Halliday, 1993 i drugde) u okviru ove škole razvijen je tranzitivni metod analize gramatički metaforičnih reprezentacija značenja u diskursu. ${ }^{9}$ Ovo je široko prihvaćen i primenjivan metod $u$ ispitivanjima načina oblikovanja znanja o prošlosti i formiranju statova o istorijskim događajima kroz program obaveznog obrazovanja (v. Bernard, 2003; Coffin, 2003; Moss, 2010; Rajadran, 2012; Московљевић Поповић и Динић Маринковић, 2014). Tranzitivni metod primenjen je i u istraživanju predstavljenom u ovom radu, jer, kako je uvideo Halidej temeljno isputujući prirodu pisanog školskog jezika, "stručno" ili školsko "znanje jeste regramatikalizacija iskustva" (Halliday, 1998). Pored toga, kako primećuje Rajandran (2012: 317), tranzitivnost kao metod obezbeđuje zajednički terminološki aparat za razmatranje i razumevanje jezičkih strategija u udžbeničkom žanru.

Tokom analize gramatički metaforičnih reprezentacija značenja u obrađenoj građi utvrđeno je da se kao učesnici u događajima, ukoliko su uopšte i iskazani, najčešće javljaju države i njene institucije, državni i vojni savezi, prestonice, gradovi, oblasti, odnosno da su metonimijski prenosi vrlo frekventan izraz u analiziranim udžbenicima. Ne želeći da ulazimo u teorijsku raspravu o saodnosu metafore i metonimije, niti da se opredeljujemo da li metonimija okida gramatičku metaforu ili je sastavni deo procesa metaforizacije gramatičke strukture ${ }^{10}$, a u cilju što podrobnijeg opisa figurativnog jezika koji preovladava u udžbenicima istorije, posebno su izdvojeni, analizirani i prikazani obrasci metonimijskih prenosa u analiziranoj građi.

\subsection{Izdvajanje gramatički metaforičnih reprezentacija značenja}

Gramatička metafora je konstrukt potekao u sistemskoj funkcionalnoj lingvistici M. A. K. Halideja kojim se označava „indirektno kodiranje značenja u gramatici, odnosno posredovana konceptualizacija putem gramatičkih/sintaksičkih sredstava" (Halliday i Matthiessen, 2004: 586-658; Martin, 2013). Osnovu za ovaj konstrukt čini shvatanje da je svakoj gramatičkoj klasi svojstveno određeno gramatičko i semantičko značenje (princip dvaju značenja). Tako je, u najkraćem, glagolima svojstveno

\footnotetext{
${ }^{9} \mathrm{O}$ konceptu gramatičke metafore i metodi analize $v$. u tački 3.1.

${ }^{10}$ Ovo je velika tema. O naznakama problematike v. npr, Nunberg, 1995 i Radden \& Kövecses, $1999: 37$.
} 
značenje akcije; imenicama s obeležjem [+animatnost] svojstveno je značenje aktera, a imenicama s obeležjem [-animatnost] značenje stvari. U slučaju narušenosti principa dvaju značenja, tj. kada semantičke kategorije nisu realizovane odgovarajućim gramatičkim kategorijama, odnosno odgovarajućim morfosintaksičkim jedinicama, na delu je gramatički metaforična reprezentacija značenja ${ }^{11}$.

$\mathrm{U}$ analizi građe u ovom radu primenjen je tranzitivni metod sistemske funkcionalne lingvistike. Prema SFL-u, tranzitivnost predstavlja iskustvenu komponentu pojmovne metajezičke funkcije (Halliday i Matthiessen, 2004: 589594). ${ }^{12}$ Kako navode Halidej i Methenzen (ibid.), čovek „iskustvo" poima kao „redosled događaja". Svaki događaj sastoji se od (1) procesa, (2) učesnika u procesu, i (3) okolnosti - vreme, mesto, način, uzrok, ... . Različiti modeli događaja preslikavaju se na rečeničnu strukturu, a jezički mehanizam kojim se to postiže jeste tranzitivnost. Drugim rečima, tranzitivnost je oznaka za jezički mehanizam koji putem gramatičke strukture nezavisne predikatske rečenice formira iskustvo.

$\mathrm{U}$ tranzitivnom metodu jedinica analize je nezavisna predikatska rečenica koju čine tri glavna funkcionalna elementa - proces, učesnici i okolonosti. Kada je reprezentacija faktičkog stanja kongruentna, proces je iskazan glagolom u stanju aktiva, učesnici u procesu izraženi su nominalnim konstrukcijama sa obeležjem [+animatnost], a okolnosti su iskazane sintaksičkim jedinicama sa priloškom konstituentskom vrednošću.

Kada je ovaj model narušen, kao u sledećem primeru, reprezentacija značenja smatra se nekongruentnom, kako na jezičkom planu, tako i u odnosu na neposredno iskustvo i faktično stanje koje reprezentuje, odnosno smatra se gramatički metaforičnom.

Primer:

(...) а потом наредио њихово опкољавање (...). (I8: 82)

Ovo je gramatički metaforična rečenica koja se ne slaže sa faktičkim stanjem stvari, odnosno rečenica u kojoj su u doslovnoj interpretaciji narušeni istinosni uslovi, budući da je proces (da se opkole) realizovan kao nominalna konstrukcija (njihovo opkoljavanje), odnosno postvaren.

Tranzitivni metod poseduje i bogat i razgaranat aparat za analizu semantičkh uloga i načina njihovog preslikavanja na sintaksičku strukturu. Neke od uloga su, npr:

${ }^{11}$ O presecima i razlikama koncepata gramatičke i pojmovne metafore v. npr, Ritchie \& Zhu, 2015.

${ }^{12}$ O multiperspektivnom modelu jezika prema SFL v. Martin, 1997; Halliday i Matthiessen, 2004; Martin, 2013: 24. 
akter, nosilac, govornik, fenomen, napadač, napadnuti (up. Rajadran, 2012 i Barnard, 2010). Međutim, u skladu sa osnovnim ciljem ovoga rada, a to je izdvajanje dominantnih tipova figurativnog jezika, smatrali smo da u prvom koraku valja izvršiti analizu vrsta prenosa na nivou nezavisne klauze, te se detaljnom obradom semantičkih uloga za potrebe ovog rada nismo bavili.

\subsection{Izdvajanje obrazaca metonimijskih prenosa}

Za jedinicu analize uzeta je referencijalna metonimija. Odlike referencijalne metonimije su sledeće: (1) metonim je nominalna konstrukcija u ulozi argumenta glagola; (2) metonim predstavlja neko od obeležja impliciranog/ciljnog entiteta; (3) u doslovnoj interpretaciji istinosni uslovi su narušeni; i (4) za razumevanje metonimije presudna je uloga konteksta (Warren, 2006: 19-40; Rasulić, 2010: 54). Zbog specijalne namene građe koja je predmet naše analize i podržavajući mišljenje „da je za metonimijski prenos najrelevantniji upravo onaj nivo kategorizacije koji odgovara neposrednom, konkretnom čovekovom telesnom i društveno-kulturnom iskustvu" (Rasulić, 2010: 56), sprovedena je analiza koja se odnosi na specifičan/konkretan nivo kategorizacije metonimijskih prenosa.

Primeri metonimijskih prenosa ekscerpirani su u odnosu na pretpostavljene, već prepoznate i u literaturi predstavljene izvorne entitete metonimijskih obrazaca (Nunberg, 1995; Radden i Panther, 1999; Radden i Kövecses, 1999; Market i Hahn, 2002; Stefanovich i Gries, 2006; Hilpert, 2006; Stefanowitsch i Gries, 2006; Rasulić, 2010; Littlemore, 2015). Međutim, posebno zbog slučajeva u kojima je i izvor i cilj metonimijskog prenosa ČOVEK (grupa ili pojedinac), u izdvajanju i kategorizaciji metonimijskih prenosa u analiziranoj građi vodili smo se i sledećim opštim principima koji su opisani u konsultovanoj literaturi:

- Realizacija (metonimija) je nedovoljno specifikovana (A+B).

Pr: Еснаф се (...) старао о производњи. (I6: 71)

- Odnos bliskosti se zasniva na partonimiji (A je deo B).

Pr: (...) генерал Степа Степановић (...) извео чувени марш на Дрину. (I8: 81)

- Odnos bliskosti se zasniva na kvalifikaciji ili taksonimiji (A je vrsta B).

Pr: Током ове епохе људско биће је постигло огроман напредак(...). (I5: 16)

- Metonimija se može javiti ukoliko je ciljni entitet nedvosmisleno dostupan/razumljiv i ukoliko kontekst direktno upućuje na njega. 
Pošto je metonimija visoko zastupljena u tekstu analiziranih udžbenika, predmet analize predstavljene u ovom radu ograničen je na sledeće tipove metonimijskih prenosa:

(1) one u kojima je izvorni pojam realizovan toponimima koji označavaju imena država, oblasti i gradova, npr: Црна Гора је одмах објавила рат Аустроугарској и Немачкој.(I8: 81), Очекиване турске нападе Деспотовина није спремно дочекала. (I6: 124), (...)Цариград и Солун успели су да одоле нападима варвара. (I6: 67);

(2) one u kojima izvorni pojam označava institucije sistema, npr: (...) феудални суд који је судио и глобио грађанство. (I6: 67);

(3) one u kojima se izvorni entitet odnosi na lokaciju, a realizovan je leksičkim jedinicima iz opšteg leksičkog fonda, npr: (...) између града и села дошло је до велике поделе рада. (I6: 70);

(4) one u kojima je izvorni pojam čovek, a iskazan je etnonimom, antroponimom ili leksičkom jedinicom koja označava kakvu društvenu funkciju ili titulu, npr: Прве на удару Турака биле су (...). (I6: 117), (...) највећи територијални обим достигло под Трајаном.(I5: 64).

Metonimijski prenosi ekscerpirani su na sledeći način. Najpre su iz prethodno konstruisanih frekvencijskih rečnika udžbenika ${ }^{13}$ izdvojene lekseme koje smo smatrali potencijalnim izvornim entitetima metonimijskih prenosa (toponimi, lekseme koje označavaju institucije i lokacije, antroponimi, etonimi, državne funkcije i titule). Zatim je uz pomoć programa AntConc ${ }^{14}$ ustanovljeno da li se instancije izdvojenih leksičkih jedinica u tekstu udžbenika javljaju u funkciji učesnika metonimijskih prenosa. Pošto ovaj program automatski konstruiše konkordance, tj. kontekst u kome su tražene leksičke jedinice upotrebljene u tekstu, na osnovu dobijenih rezulata izvršena je i analiza obrazaca metonimijskih prenosa koji su prisutni u udžbenicima istorije za više razrede osnovne škole. Osnovni parametar prilikom izdvajanja metonimijskih obrazaca bio je kontekst (narušenost istinosnih uslova u doslovnoj interpretaciji i nedvosmisleno upućivanje na ciljni pojam metonimijskog prenosa).

\footnotetext{
${ }^{13} \mathrm{O}$ načinu konstruisanja frekvencijskih rečnika udžbenika, odnosno frekvencijskih lematiziranih lista reči $v$. Динић, 2014; ДинићМаринковић, 2016 і ДинићМаринковић, 2017.

${ }_{14}$ "AntConc" (Verzija 3.4.3) - http://www.laurenceanthony.net
} 


\section{Rezultati istraživanja}

\subsection{Gramatička metafora u udžbenicima istorije za osnovnu školu}

Među utvrđenim gramatički metaforičnim reprezentacijama značenja u udžbenicima istorije za osnovnu školu izdvajaju se sledeći tipovi.

1. Reifikacija, tj. postvarivanje, rezultat je gramatičke metafore kojom se procesi predstavljaju kao stvari, a koja se ostvaruje putem nominalizacije. Npr:

Употреба метала донела је и нова занимања: рудар, ливац, ковач. (I5: 17)

(...) прво померање становништва узроковао је начин освајања Османлија.

(I6: 127)

Одлука о рату (...) била је већ уобличена у двема престоницама Централних сила. (I8: 74)

Упаде аустроугарски трупа у Србију (...) карактерисао је окрутан однос према цивилном становништву. (I8: 85)

До коначног пробоја Солунског фронта дошло је тек две године касније. (I8: 84)

Kao što se iz navedenih primera vidi, najčešće nije samo glagol nominalizovan, već su cele klauze pretvorene u imeničke sintagme, odnosno čitav događaj je reprezentovan kao stvar.

2. Deagentizacija predstavlja jezički mehanizam kojim se učesnici u događaju brišu i svode na okolnosti. Ostvaruje se u nezavisnim klauzama čiji je glagol u predikatu u neutralnom (bezličnom, impersonalnom) obliku ${ }^{15}$ ili u stanju pasiva (participskog ili refleksivnog). Iako se gl. u stanju pasiva smatra nekongruentnim u odnosu na faktičko stanje koje reprezentuje, u primerima ćemo označiti učesnike u procesu koji su realizovani kao okolnosti događaja, jer su oni cilj prenosa.

у мајсторским радионицама, дошло се, на пример, до сазнања како се праве боje. (I6: 77)

Одлука о рату (...) била је већ уобличена у двема престоницама Централних сила. (I8: 74)

Највише због тога, у Бечу се, после 1928. године, размишљало о подели Србије.(18: 74)

(...) али је у Бечу и Берлину атентат схваћен као повод за рат. (I8: 74)

15 O obezličenim rečenicama v. npr, Станојчић и Поповић, 1992: 243-245. 
До коначног пробоја Солунског фронта дошло је тек две године касније [Ø]. (I8: 84)

3. "Okolnosnost" bi mogao biti naziv za gramatičku metaforu čijom upotrebom procesi postaju okolnosti. Ovaj prenos je, zapravo, reifikacija i ostvaruje se procesom nominalizacije, ali je usled rekcije glagola uz koje se javlja realizovan predloško-padežnom konstrukcijom. Budući da tranzitivni metod predloškopadežnu konstrukciju prepoznaje kao adverbijalnu odredbu, te joj stoga dodeljuje značenje okolnosti, ovaj tip upotrebe gramatičke metafore smo, za sada, odvojili u posebnu grupu.

Поред налета варвара, Западно римско царство су потресале непрестане борбе за престо. (I5: 71)

у жестоком судару и обостраној великој погибији, смрт су нашла два владара, кнез Лазар и султан Мурат.(I6: 119)

После губитка Београда за врло кратко време изграђено је Смедерево. (I6: 124)

у сукоб Аустро-Угарске и Србије уплела се и Немачка.(I8: 74)

Kao što se iz datih primera vidi, u okviru jedne nezavisne klauze najčešće je pristuno više od jednog tipa prenosa/figura, što pokazuje koliko je kompleksan i zahtevan prostupak raspakivanja gramatički metaforičnih rečenica koji učenici moraju da realizuju kako bi razumeli tekst koji čitaju.

\subsection{Obrasci metonimjskih prenosa u udžbenicima istorije za osnovnu školu}

U analiziranoj građi izdvojeni su sledeći obrasci metonimijskih prenosa:

\begin{tabular}{l|l}
\hline \hline \multicolumn{1}{c|}{ OBRAZAC PRENOSA } & \multicolumn{1}{c}{ Primer } \\
\hline \hline ČOVEK/LJUDSKO BIĆE - LJUDI & $\begin{array}{l}\text { Пре око пола милиона година човек је научио } \\
\text { да говори (...). (I5: 16); Човек млађег каменог } \\
\text { доба је припитомио животиње. (I5: 17) }\end{array}$ \\
\hline
\end{tabular}




\begin{tabular}{|c|c|}
\hline $\begin{array}{l}\text { ETNONIM - UPRAVA/ČELNI LJUDI TE } \\
\text { ZEMLJE }\end{array}$ & $\begin{array}{l}\text { Римљани су освојене области претварали у } \\
\text { провинције. (I5: 63) }\end{array}$ \\
\hline ETNONIM - VOJSKA & $\begin{array}{l}\text { Римљани су избегавали велике битке (...). (I5: } \\
\text { 62); (...)уништени су у првом судару с Турцима. } \\
\text { (I6: 65); (..) Бугари су ушли у Врање (...).(I8: } \\
\text { 82) }\end{array}$ \\
\hline $\begin{array}{l}\text { DRŽAVA - } \\
\text { UPRAVA/VOJSKA/STANOVNIŠTVO }\end{array}$ & $\begin{array}{l}\text { (...) у грађанским ратовима који су Рим } \\
\text { потресали (...). (I5: 60); Крсташким } \\
\text { државама претиле су околне муслиманске } \\
\text { земље. (I6: 65) }\end{array}$ \\
\hline $\begin{array}{l}\text { OBLAST/GRAD - } \\
\text { UPRAVA/VOJSKA/STANOVNIŠTVO }\end{array}$ & $\begin{array}{l}\text { (...) дошли у сукоб са Тарентом, богатим } \\
\text { градом на југу Италије. (I5: 61); Дачани су } \\
\text { често пљачкали провинције на северу. (I5: 64) }\end{array}$ \\
\hline INSTITUCIJA - LJUDI KOJI JE ČINE & $\begin{array}{l}\text { У вођењу спољне политике саветовали су се са } \\
\text { Сенатом. (I5:61);Црква је спречавала ширење } \\
\text { нових открића. (I6: 77);(..)компромис између } \\
\text { ставова српске владе и Југословенског } \\
\text { одбора. (I8: 91) }\end{array}$ \\
\hline $\begin{array}{l}\text { VLADAR - PERIOD VLADAVINE/EPOHA } \\
\text { KOJU JE OBELEŽIO }\end{array}$ & $\begin{array}{l}\text { (...) доба принципата (од Октавијана Августа } \\
\text { до Диоклецијана) и доба домината (од } \\
\text { Диоклецијана до (...). (I5: 65); У доба } \\
\text { деспота Ђурђа Бранковића учестали су (...) } \\
\text { сукоби. (I6: 124) }\end{array}$ \\
\hline $\begin{array}{l}\text { VOJSKOVOĐA - VOJSKA KOJOM } \\
\text { KOMANDUJE }\end{array}$ & $\begin{array}{l}\text { Пир је римску војску поразио (..). (I5: 61); (...), } \\
\text { али је претрпела два велика пораза од } \\
\text { генерала Хинденбурга. (I8: 76) }\end{array}$ \\
\hline $\begin{array}{l}\text { DRUŠTVENI SLOJ - GRUPA KOJA MU } \\
\text { PRIPADA }\end{array}$ & $\begin{array}{l}\text { Папском позиву одазвали су се и сиромашни } \\
\text { слојеви друштва. (I6: 64); Витешко- } \\
\text { монашки редови градили су утврђења (...). } \\
\text { (I6: 65) }\end{array}$ \\
\hline $\begin{array}{l}\text { MESTO OBAVLJANJA POSLA - LJUDI } \\
\text { KOJI TU RADE }\end{array}$ & $\begin{array}{l}\text { У мајсторским радионицама }{ }^{16}, \text { дошло се, на } \\
\text { пример, до сазнања како се праве боје. (I6: 77) }\end{array}$ \\
\hline $\begin{array}{l}\text { KOLEKTIVNA KVALIFIKACIJA PREMA } \\
\text { VERSKOJ PRIPADNOSTI - } \\
\text { VOJNICI/UČENISNICI U SUKOBU }\end{array}$ & $\begin{array}{l}\text { (...)муслимани су водили рат против } \\
\text { „неверника" хришћана.(16: 64) }\end{array}$ \\
\hline
\end{tabular}

\footnotetext{
${ }^{16}$ Iako Voren (Warren, 2006: 19) navodi da je u slučaju referencijalne metonimije metonim nominalna konstrukcija u ulozi argumenta glagola, ipak držimo da je u ovoj deagentizovanoj konstrukciji PPK sa značenjem mesta metonim. Naime, smatramo da je upravo usled deagentizacije ostvaren metonimijski prenosLOKACIJA - LJUDI KOJI U NJOJ RADE. Kako se iz priloženih primera može zapaziti, referencijalna metonimija čiji izvor nije argument glagola nije redak prenos u diskursu udžbenika istorije.
} 


\begin{tabular}{|c|c|}
\hline $\begin{array}{l}\text { NASELJENO MESTO - } \\
\text { UPRAVA/VOJSKA/STANOVNIŠTVO }\end{array}$ & $\begin{array}{l}\text { Крсташке државе губиле су град за градом. } \\
\text { (..) (I6: 65); Обогатили су се италијански } \\
\text { градови (..). (I6: 66) }\end{array}$ \\
\hline NASELJENO MESTO - STANOVNIŠTVO & $\begin{array}{l}\text { (...) између града и села дошло је до велике } \\
\text { поделе рада. (I6: 70); Нова престоница брзо } \\
\text { је оживела. (I6: 122) }\end{array}$ \\
\hline $\begin{array}{l}\text { NASELJENO MESTO - NAČIN ŽIVOTA U } \\
\text { NJEMU }\end{array}$ & $\begin{array}{l}\text { По томе се средњовековни град разликовао } \\
\text { од села. (I6: 70) }\end{array}$ \\
\hline $\begin{array}{l}\text { STRANE SVETA - DRŽAVE KOJE } \\
\text { ZAUZIMAJU ODREĐEN POLOŽAJ U } \\
\text { ODNOSU NA OVAJ ORIJENTIR }\end{array}$ & $\begin{array}{l}\text { Ојачале су трговинске везе између истока и } \\
\text { запада. (I6: 66) }\end{array}$ \\
\hline $\begin{array}{l}\text { DRŽAVA - ČELNI } \\
\text { LJUDI/UPRAVA/VOJSKA }\end{array}$ & $\begin{array}{l}\text { (...) српске земље и босанска држава } \\
\text { делиле су два љута противника - Турску и } \\
\text { Угарску. (І6: 121); С околним државама } \\
\text { самостално су преговарали и склапали } \\
\text { уговоре.(I6: 125); } \\
\text { Бугарска је одмах потписала капитулацију. (I8: } \\
\text { 84); Повод да Аустро-Угарска званично објави } \\
\text { рат Србији(...). (I8: 74) }\end{array}$ \\
\hline ETNONIM - VOJSKA & $\begin{array}{l}\text { Турци су (...) заузели Цариград и срушили } \\
\text { Византијско царство. (I6: 124); Кренули су у } \\
\text { офанзиву и Италијани, (...). (I8: 76) }\end{array}$ \\
\hline INSTITUCIJA - LJUDI KOJI JE ČINE & $\begin{array}{l}\text { Српска црква је управо у кнезу Лазару видела } \\
\text { јединог државника (..). (I6: 118); } \\
\text { Аустроугарска влада била је незадовољна } \\
\text { одговором. (I8: 74); Бечки двор је за } \\
\text { организовање атентата оптужио српску владу. } \\
\text { (I8: 74) }\end{array}$ \\
\hline $\begin{array}{l}\text { UPRAVITELJ OBLASTI - OBLAST } \\
\text { KOJOM UPRAVLJA }\end{array}$ & $\begin{array}{l}\text { Краљ Вукашин и његов брат Урош били су } \\
\text { први на удару и први осетили опасност од } \\
\text { Турака. (I6: 117) }\end{array}$ \\
\hline $\begin{array}{l}\text { VOJNO-POLITIČKI SAVEZ - ČLANOVI } \\
\text { SAVEZA }\end{array}$ & $\begin{array}{l}\text { Антанта је тек (...) направила јединствен ратни } \\
\text { план. (I8: 76); (..) дошло је до обостране } \\
\text { офанзиве Централних сила и Антанте. (I8: } \\
75)\end{array}$ \\
\hline $\begin{array}{l}\text { MESTO U KOM SE INSTITUCIJA } \\
\text { NALAZI - LJUDI KOJI JE ČINE }\end{array}$ & $\begin{array}{l}\text { (...) али је у Бечу и Берлину атентат схваћен } \\
\text { као повод за рат. (I8: } 74 \text { ); Хрватски сабор је } \\
\text { раскинуо све државно-правне везе са Бечом и } \\
\text { Будимпештом (...). (I8: 91) }\end{array}$ \\
\hline
\end{tabular}


Pored izdvajanja samih obrazaca važno je istaći i da su metonimijski prenosi jako frekventno diskurzivno sredstvo u analiziranim udžbenicima. Naime, većina razmatranih leksema u više od $50 \%$ svojih pojavljivanja u tekstu analiziranih udžbenika funkcioniše kao izvor metonimijskih prenosa. Na primer: čovek $(10 / 10)^{17}$, Rimljanin (31/43); Kartagina (5/7); Rimsko carstvo (13/21); Cezar (2/2); Antanta $(13 / 20)$; crkva $(16 / 21)$.

\subsubsection{Varijabilnost metonimijskih prenosa}

Kao što je u uvodnom delu rada naglašeno, ispitivanje varijabilnosti upotrebe figurativnog jezika u udžbenicima značajno je zbog razrešenja pitanja da li je upotreba određenog tipa figure u udžbenicima istorije isključivo odlika žanra ili je zavisna i od tema koje se u udžbenicima obrađuju. Kako bismo odgovorili na ovo pitanje, izvršeno je poređenje upotrebe izdvojenih obrazaca metonimijskih prenosa u odnosu na temu u kojoj se javljaju18. Rezultati analize predstavljeni su u Tabeli 2.

Tabela 2: Varijabilnost upotrebe obrazaca metonimijskih prenosa u udžbenicima istorije ${ }^{19}$

\begin{tabular}{|c|c|c|c|c|c|c|}
\hline $\begin{array}{l}\text { Obrasci } \\
\text { metonimijskog prenosa }\end{array}$ & 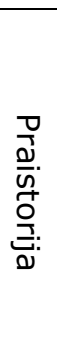 & 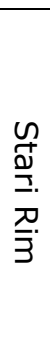 & 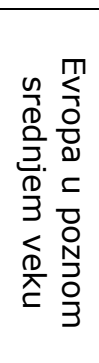 & 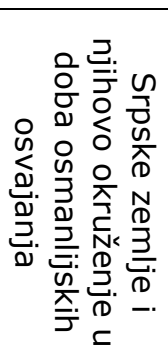 & 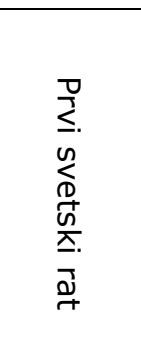 & 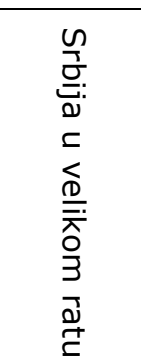 \\
\hline ČOVEK - LJUDSKI ROD & + & - & - & - & - & - \\
\hline $\begin{array}{ll}\text { ETNONIM } & - \\
\text { UPRAVA/VOJSKA/STANOVNIŠTVO }\end{array}$ & - & + & $\begin{array}{c}- \\
\text { stan. }\end{array}$ & +vojska & +vojska & +vojska \\
\hline $\begin{array}{l}\text { DRŽAVA - UPRAVA/VOJSKA/ } \\
\text { STANOVNIŠTVO }\end{array}$ & - & + & + & + & -stan. & -stan. \\
\hline $\begin{array}{l}\text { OBLAST/GRAD - UPRAVA/VOJSKA/ } \\
\text { STANOVNIŠTVO }\end{array}$ & - & + & + & - & + & + \\
\hline INSTITUCIJA - LJUDI KOJI JE ČINE & - & + & + & + & + & + \\
\hline VLADAR - PERIOD VLADAVINE & - & + & - & + & - & - \\
\hline
\end{tabular}

\footnotetext{
${ }^{17}$ Brojevi u zagradi odnose se na broj pojavljivanja date leksičke jedinice u analiziranoj građi. Prvi broj odnosi se na broj pojavljivanja koja u analiziranoj građi predstavljaju izvore metonimijskih prenosa, a drugi broj jeste ukupna frekvencija date lekseme u obrađenom korpusu, tj. u našem slučaju uzorku/temi.

${ }^{18}$ Analiza varijabilnosti tipova gramatičke metafore nije izvršena jer takva analiza iziskuje posebno obeležavanje/anotaciju korpusa. Takođe, nivo izvršene analize gramatičke metafore u ovom istraživanju nije dovoljno specifičan/dubok da bi se uočila varijabilnost na mestima na kojima može biti prisutna. Tipovi prenosa koji su izdvojeni u ovom istraživanju svojstvo su pisanog školskog jezika (uopšte) i udžbenika istorije.

${ }^{19} \mathrm{U}$ tabeli simboli "+" i ",-" označavaju prisustvo/odsustvo određenog tipa prenosa u datoj temi. Polja s vrednošću "-stan." znače da je iz grupe ciljnih entiteta datog prenosa izostavljeno stanovništvo, a polja s vrednošću "+vojska" da je to jedini prisutni ciljni entitet iz datog obrasca u pripadajućoj temi.
} 


\begin{tabular}{|l|c|c|c|c|c|c|}
\hline $\begin{array}{l}\text { VOJSKOVOĐA - VOJSKA KOJOM } \\
\text { KOMANDUJE }\end{array}$ & - & + & - & - & + & + \\
\hline DRUŠTVENI SLOJ - LJUDI KOJI GA ČINE & - & - & + & - & - & - \\
\hline MESTO RADA - LJUDI KOJI TU RADE & - & - & + & - & - & - \\
\hline VERSKA PRIPADNOST - VOJSKA & - & - & + & - & - & - \\
\hline MESTO - NAČIN ŽIVOTA & - & - & + & - & - & - \\
\hline UPRAVITELJ TERITORIJE - TERITORIJE & - & - & - & + & - & - \\
\hline NASELJE - STANOVNIŠTVO & - & - & - & + & - & - \\
\hline VOJNO-POLITIČKI SAVEZ - ČLANICE & - & - & - & - & + & + \\
\hline $\begin{array}{l}\text { GRAD U KOM SE INSTITUCIJA NALAZI - } \\
\text { LJUDI KOJI ČINE INSTITUCIJU }\end{array}$ & - & - & - & - & & + \\
\hline
\end{tabular}

Dobijeni rezultati pokazuju da postoji varijabilnost u upotrebi metonimijskih prenosa u odnosu na teme, a ona se ogleda u različitim obrascima prenosa koji se u njima ostvaruju. Razlog ovome, jednim delom, jeste tematska zavisnost diskurzivnih sredstava.

Tako se, na primer, obrazac prenosa čovek - ljudski rod javlja jedino u okviru teme „Praistorija", dok drugih izdvojenih obrazaca prenosa u ovoj temi nema. Isto tako, metonimijski prenosi vojno-politički savez - članice i grad u kom se institucija nalazi - ljudi koji je čine javljaju se jedino u okviru tema u kojima se obrađuje period I svetskog rata. Da u navedenim slučajevima, kao i u slučaju svih prenosa koji se ekskluzivno pojavljuju u po jednoj temi (v. Tabelu 2), teme, same po sebi, diktiraju izbor prenosa, nije upitno, i može se reći da se tu nisu našli posebnim zalaganjem autora teksta.

Međutim, kada se obrati pažnja na obrasce metonimijskih prenosa koji se javljaju u više različitih tema, dolazi se do zanimljivih uvida. Na primer, obrazac prenosa vojskovođa - vojska kojom komanduje, koji je očekivan, a i, iz rezultata vidimo, frekventan prenos u udžbenicima istorije, (ne)očekivano izostaje u temi "Srpske zemlje i njihovo okruženje u doba osmanlisjkih osvajanja". Obrazac etnonim uprava/vojska/stanovništvo počevši od srednjeg veka prestaje da upućuje na stanovništvo, a u temama koje se tiču rata služi jedino kao izvorni domen za vojsku. Slično ovome, iz obrasca država - uprava/vojska/stanovništvo u temama u kojima se obrađuje rat, izbrisano je stanovništvo. Ovaj vid varijabilnosti ukazuje i na namernu, odnosno svesnu upotrebu figura, kako bi se kod adresata postigao željeni pogled na stvari. 


\section{Diskusija}

Osnovni cilj ovoga rada jeste izdvajanje dominantnih tipova figurativnog jezika u udžbenicima istorije za osnovnu školu. Kao dominantni tipovi izdvojeni su gramatička metafora i obrasci metonimijskih prenosa.

Kada postavljenom problemu pristupimo iz ugla usvanja jezika u kasnijem periodu, ili iz perspektive usvajanja i razvoja pismenosti, izdvojene gramatičke metafore ni po čemu se ne razlikuju od onih već opisanih u literaturi (up. Halliday, 1993; Halliday i Martin, 1993; Halliday, 1998).

Kada posmatramo kakav diskurs i svetonazor formiraju analizirani tipovi figurativnog jezika u obrađenom korpusu udžbenika, nalazimo sledeće.

Nominalizacija, odnosno reifikacija kreira postvaren diskurs, u kome istorijski događaji i procesi postaju stvari. Ovo je primećeno i u istraživanju Šefer i sar. "y друштвеним наукама, на пример у историји, (...), живот је апсолутно умртвљен, (...), већ и зато што се" (događaji) „излажу у форми извештаја, а не приче." (Шефер, Лазаревић и Стевановић, 2008:352). Međutim, rezultat nominalizacije nije samo zarobljavanje dinamične prirode procesa. Kako se iz navedenih primera vidi ( $\mathrm{v}$. t. 4.1), nominalizacijom, najčešće, nije obuhvaćen samo proces, već čitav događaj, odnosno nominalizuje se cela klauza. Tako je i u primeru nominalne konstrukcije "Upadi austrougarskih trupa u Srbiju", u kojoj je poimeničeni proces (upad) centar imeničke sintagme, a akteri (austrougarske trupe) realizovani kao njen zavisni član. Dakle, pored postvarivanja, odabirom ovog jezičkog sredstva izbegava se i pripisivanje odgovornosti, kao i eksplicitno navođenje uzroka istorijskih događaja (up. Barnard, 2003; Coffin, 2006; Moss, 2006 i 2010; Rajandran, 2012). Kada se sve navedeno uzme u obzir, nominalizacija stvara otklon prema istorijskim događajima i procesima koje reprezentuje, čime onemogućava učenike da se prema istorijskim događajima o kojima saznaju i odrede.

Deagentizacija kreira diskurs, a posledično, i predstavu o svetu bez aktera. Neizricanje učesnika u događaju, ili svođenje učesnika u istorijskim događajima na okolnosti, ne samo da minimizuje ulogu pojedinca/ljudi u istorijskim događajima i procesima, već i više od toga - dovodi do stvaranja slike o tome kako su događaji iz prošlosti kakve prirodne datosti, najčešće negativne, kao vremenske nepogode koje su došle same od sebe (kao „vekovne kiše" iz vedra neba), na koje niko nije mogao da utiče. Brisanje učesnika u procesu ili njihovo smeštanje u okolnosti događaja praćeno je pasivizacijom i deagentizacijom, pa su tako u ovim slučajevima, i sami procesi predstavljeni kao stanja. Konstrukcije u kojima su učesnici u događaju 
reprezentovani/realizovani kao okolnosti događaja (što posebno važi za uloge aktera u svetskim ratovima, npr: Одлука о рату (...) била је већ уобличена у двема престоницама Централних сила; Највише због тога, у Бечу се, (...), размишљало о подели Србије.; (...) али је у Бечу и Берлину атентат схваћен као повод за рат.), po pravilu u sebi sadrže još jednu figuru - metonimijski prenos, kao da akteri sintaksičkim procesom democije nisu dovoljno neutralisani, već da je potrebno da se u što većoj meri onemogući uspostavljanje veze između događaja, aktera i odgovornosti.

Kada je o obrascima metonimijskih prenosa reč, njihova upotreba u tekstu analiziranih udžbenika doprinosi formiranju dehumanizovanog diskursa ( $v$. izdvojene obrasce prenosa u Tabeli 2). Kada se posmatra uporeba različitih obrazaca u odnosu na temu u kojoj se javljaju, primetna je tendencija da što smo na vremenskoj liniji bliže sadašnjosti, to se češće koriste obrasci u kojima se izvor i cilj prenosa sve više udaljavaju, kao i onih u kojima postoji "slaganje" više prenosa. Ako upotrebu metonimije u diskursu razumemo i kao sredstvo za izbegavanje pripisivanja odgovornosti, nameće se zaključak da se pripisivanje odgovornosti namerno izbegava u temama iz bliže prošlosti.

Sprovedena analiza varijabilnosti metonimijskih prenosa ukazuje na to da je upotreba određenog tipa prenosa tematski zavisna, ali na dva načina. U jednom delu, određeni obrasci ekskluzivno pripadaju pojedinačnim temama usled istorijskih događaja i procesa o kojima govore, kakav je, npr, slučaj sa prenosom čovek - ljudski rod u temi „Praistorija". Sa druge strane, primećeno je odsustvo pojedinih obrazaca u temama u kojima je njihovo pojavljivanje očekivano. Tako je, npr, u slučaju prenosa vojskovođa - vojska kojom komanduje. Ovo nam pokazuje da je upotreba određenog tipa figurativnog jezika u udžbenicima i namerna, odnosno upotrebljena sa ciljem da se kod adresata postigne određeni pogled na predstavljene događaje. Odsustvo navedenog prenosa u temi "Srpske zemlje (...) u doba osmanlijskih osvajanja" pokazuje da se vojska neće imenovati vojskovođama iz nacionalne istorije koji se u interpretaciji istorijskih događaja ne razumeju kao pobednici.

\section{Zaključci}

$\mathrm{Na}$ osnovu istraživanja predstavljenog u ovom radu izdvojeni su dominantni oblici fugurativnog jezika u udžbenicima istorije za osnovnu školu - gramatička metafora i metonimijski prenosi. 
Nad izdvojenim obrascima metonimijskih prenosa izvršena je analiza varijabilnosti, i ustanovljeno je da je upotreba metonimijskih prenosa zavisna od tema koje se u analiziranim udžbenicima obrađuju, ali na dva različita načina. Utvrđeno je da postoje obrasci metonimijskih prenosa koji se, zbog svoje specifičnosti, javljaju samo u okviru pojedinih tema. S druge strane, utvrđeno je da obrasci prenosa koji su širokog polja upotrebe (oni koji se javljaju u više različitih tema) izostaju sa očekivanih mesta, posebno kada akterima iz nacionalne istorije treba pripisati nepobedničke uloge. Takođe, ustanovljeno je da što smo bliže savremenom trenutku na vremenskoj osi, to se više javljaju prenosi kojima se u potpunosti izbegava imenovanje aktera istorijskih događaja, što ukazuje na upotrebu metonimijskih prenosa kao diskurzivnog sredstva za izbegavanje pripisivanja odgovornosti.

Dva centralna pitanja razmatrana u ovom radu - kojim formama figurativnog jezika je neophodno da učenici ovladaju kako bi razumeli tekst udžbenika i usvajali gradivo, i kakvu sliku o svetu kreira diskurs satkan od izdvojenih figura, dobila su sledeće odgovore.

Izdvojene figure predstavljaju svojstvo pisanog školskog jezika, i to posebno udžbenika istorije i drugih društvenih nauka, kako je već prepoznato u ranije sprovedenim istraživanjima.

Kada je reč o diskursu koji tvore izdvojene figure, iz rezultata sprovedene analize proizlazi da ustanovljene forme figurativnog jezika formiraju postvaren i deagentizovan diskurs, u kome nema niti procesa, niti učesnika u istorijskim događajima i procesima. Učesnici su prikriveni u okolnosti događaja, dok su procesi predstavljeni, u najboljem slučaju, kao stanja, a najčešće kao stvari. Takav diskurs podržava ideju o (istorijskom) determinizmu, čak i predestinaciji i fatumu, i kreira sliku o svetu u kome su društveni događaji i procesi nužne datosti, na koje pojedinac nikako ne može uticati. Kada se ovome dodaju i utvrđeni obrasci metonimijskih prenosa, u kojima, ne samo izvor, već ni cilj prenosa u najvećem broju slučajeva ne upućuje direktno na konkretne aktere, dobijamo jedan depersonalizovani diskurs, koji otežava uspostavljanje aktivnog i osvešćenog odnosa prema događajima iz prošlosti. 


\section{Izvori:}

I5 - Недељковић, 3., Стефановић, и Д. Ферјанчић. С. (2008). Историја. Београд: Завод за уџбенике и наставна средства.

16 - Михаљчић, Р. (2010). Историја.Београд: Завод за уџбенике и наставна средства.

I8 - Рајић, С., Николић, К., и Јовановић, Н. (2008). Историја. Београд: Завод за уџбенике и наставна средства.

\section{Literatura:}

Bernard, C. (2003). Pearl Harbor in Japanese High School History Textbooks: the Grammar and Semantics of Responsibility. U: Martin, J. R., \& Wodak, R. (ur.), Re/reading the past (str. 247-271). Amsterdam: John Benjamins.

Coffin, C. (1997). Constructing and Giving Value to the Past: an Investigation into Secondary School History. U: Martin, J., R., \& Frances, C. (ur.), Genre ans Institutions (str. 196-230). London: Continuum.

Coffin, C. (2003). Reconstruals of the past - settlement or invasion? The role of judgment analysis. U: Martin, J. R., \& Wodak, R. (ur.), Re/reading the past (str. 219-246). Amsterdam: John Benjamins.

Coffin, C. (2006). Historical Discourse: The Language of Time, Cause and Evaluation. London: Continuum.

Deignan, A., Littlemore, J., \& Semino, E. (ur.) (2013). Figurative Language, Genre and Register. Cambridge: Cambridge University Press.

Динић, М. (2014). Турцизми у уџбеницима историје за основну школу. Примењена лингвистика 13, 175-190.

Динић Маринковић, М. (2016). О најфреквентнијим лексичким јединицама у уџбенику историје за 5. разред. У: Kašić, Z. (ур.), Primenjena lingvistika u čast Dušanki Točanac, O jeziku i jezicima (стр. 253-270). Novi Sad - Beograd: DPLS, Filozofski fakultet Univerziteta u Novom Sadu, Filološki fakultet Univerziteta u Beogradu.

Динић Маринковић, М. (2017). Обим и структура вокабулара уџбеника за други циклус обавезног образовања. [Необјављена докторска дисертација]. Београд: Филолошки факултет.

Gibbs, R.W. (1994). The poetics of mind: Figurative thought, language, and understanding. Cambridge: University Press. 
Groves, M. F. (1995). Science Vocabulary Load of Selected Science Textbooks. School Science and Mathematics, 95(5), 231-235.

Halliday, M. A. K. (1989). Spoken and Written language. Oxford University Press.

Halliday, M. A. K. (1993). Towards a Language-Based Theory of Learning, Linguistics and Education, 5, 93-116.

Halliday, M. A. K., \& Martin, J. R. (ur.), (1993). Writing Science, Literacy and Discourse Power. London: The Falmer Press.

Halliday, M. A. K. (1998). Things and Relations: Regrammaticising Experience as Technical Knowledge. U: Martin, J. R. \& Veel, R. (ur.), Reading Science: Critical and Functional Perspectives on Discourses of Science (str. 185-235). London: Routledge.

Halliday, M. A. K., \& Matthiessen, C., (2004). An Introduction to Functional Linguistics. (Treće prerađeno izdanje). London: Hoder Arnold.

Halliday, M. A. K. (Webster, J. J. (ur.)). (2016). Aspects of Language and Learning. Verlag Berlin Heidelberg: Springer.

Handl, S. (2011). The Conventionality of Figurative language: A usage-based study. Tübingen: Narr Verlag.

Hilpert, M. (2006). Keeping an eye on the data: Metonymies and their patterns. U: Stefanowitsch, A., \& Gries, S. Th. (ur.), Corpus-based Approaches to Metaphor and Metonymy (str. 123-151). Berlin: Mouton de Gruyter.

Johansson, V. (2008). Lexical diverstity and lexical density in speech and writing: a developmental perspective. Working papers, 53, 6-79.

Katz, A., N., Cacciari, C., Gibbs, R., W., \& Turner, M. (1998). Figurative language and thought. Oxford: Oxford University Press.

Littlemore, J. (2015). Metonymy: Hidden Shortcuts in Language, Thought and Communication. Cambridge University Press.

Luke, A. (1997). Social Perspectives on Primers and Textbooks. U: Wagner, D., Street, B., Venezky, R. \& Nisbet, E. (ur.), Literacy: An International Handbook New York: Garland Press [dostupno preko: https://pages.gseis.ucla.edu/faculty/kellner/ed270/Luke/WAGNER.html]

Market, K., \& Hahn, U. (2002). Understanding metonymies in discourse. Artificial intelligence, 135, 145-198.

Martin, J. R. (1993). Life as a Noun: Arresting the Universe in Science and Humanities. U: Halliday, M. A. K. \& Martin, J. R. (ur.), Writing Science, Literacy and Discourse Power (str. 242-293). 
Martin, J. R. (1997). Analysing genre: functional parameters. U: Martin, J. R., \& Frances, C. (ur.), Genre and Instituion: Social Processes in the Workplace and School (str. 3-39). London: Continuum.

Martin, J. R. (2003). Making history: Grammar for interpretation. U: Martin, J. R., \& Wodak, R. (ur.), Re/reading the past (str. 19-57). Amsterdam: John Benjamins.

Martin, J. R., \& Wodak, R. (ur.), (2003). Re/reading the past. Amsterdam: John Benjamins.

Martin, J. R. (2009). Genre and language learning: A social semiotic perspective. Linguistics and Education, 20, 10-21.

Martin, J. R. (2013). Embedded Literacy: Knowledge as Meaning. Linguistics and Education, 24, 23-37.

Московљевић Поповић, Ј., и Динић Маринковић, М. (2014). Обрасци језичког представљања историјских личности и догађаја у дискурсу уџбеника историје. Рад изложен на међународној научној конференцији „Хуманизам: култура или илузија", 15-16. мај, 2014, Филолошки факултет, Београд, (стр. 203-204).

Moss, G. (2010). Textbook language, ideology and citizenship. Functions of Language $17(1), 71-93$.

Moss, G. (2006). Textbook langugage, teacher mediation, classroom interaction and learning process: The case of natural and social science textbooks in Barranquilla, Colombia. 33rd International Systemic Functional Congress. Proceedings, (879-894).

Nunberg, G. (1995). Transfers of meaning. Journal of Semantics, 12, 109-132.

Plut, D. (2003). Udžbenik kao kulturno-potporni sistem. Beograd: Zavod za udžbenike i nastavna sredstva.

Radden, G., \& Kövecses, Z. (1999). Towards a Theory of Metonymy. U: Radden, G., \& Panther, K. (ur.), Metonymy in Language and Thought (str. 17-59). Amsterdam: John Benjamins.

Radden, G., \& Panther, K. (ur.), (1999). Metonymy in Language and Thought. Amsterdam: John Benjamins.

Rajadran, K. (2012). Us and Them: The Portrayal of Malaysians and British in Malaysian History Textbooks. Journal of Asian and African Studies, 48(3), 313331.

Rasulić, K. (2010). Aspekti metonimije u jeziku i mišljenju. Theoria, 53(3), 49-70. 
Ritchie, L.D., \& Zhu, M. (2015). "Nixon Stonewalled the Investigation": Potential Contributions of Grammatical Metaphor to Conceptual Metaphor Theory and Analysis. Metaphor and Symbol, 30(2), 118-36.

Станојчић, Ж., и Поповић, љ. (1992). Граматика српскога језика. Београд: Завод за уџбенике и наставна средства.

Stefanowitsch, A., \& Gries, S. Th. (ur.), (2006). Corpus-based Approaches to Metaphor and Metonymy. Berlin: Mouton de Gruyter.

Steen, G. (2008). The paradox of metaphor: Why we need a three-dimensional model of metaphor. Metaphor and Symbol, 23, 4, 213-241.

Stern, J. (2006). Figurative language. U: Devitt M. \& R. Hanley (ur.), The Blackwell Guide to the Philosophy of Language (str. 168-185). Oxford: Blackwell.

Шефер, J., Лазаревић, Е., и Стевановић, J. (2008). Језик уџбеника: подстицај или препрека. Зборник Института за педагошка истраживања, 40(2), 347-368.

Temmerman, R. (2000). Towards New Ways of Terminology Description: The sociocognitive approach. Amsterdam: John Benjamins.

Warren, B. (2006). Referential metonymy. (Scripta Minora Regiae Societatis Humaniorum Litterarum Lundensis). Royal Society of Letters at Lund, Sweden [dostupno preko: https://www.researchgate.net/publication/282185079 Referential Metonymy].

Wignell, P., Martin, J. R., \& Eggins, S. (1989). The Discource of Geography: Ordering and Explaining the Experiental World. Linguistics and Education, 1, 359-391.

\section{Korišćeni alati za obradu jezičkih podataka:}

Anthony, L. (2014). AntConc (Verzija 3.4.3) [kompjuterski softver]. Tokyo, Japan: Waseda University. Dostupno preko: http://www.laurenceanthony.net 


\section{Summary \\ ON FIGURATIVE LANGUAGE IN ELEMENTARY SCHOOL HISTORY TEXTBOOKS}

The main goal of the research presented in this paper is to identify and present the dominant forms of figurative language that appear in elementary school history textbooks. Also, the typology of identified forms of figurative language is carried out, as well as an analysis of the variability of their forms.

Two dominant types of figurative language are distinguished in the analyzed textbooks grammatical metaphor and metonymic transfer. The transitive method of Systemic Functional Linguistics is applied in the analysis of the grammatical metaphor. The patterns of metonymic transfer are excerpted based on their source entities which include: toponyms, ethnonyms and anthroponyms, so as general lexis which refers to location, place, institution, and social class or title.

The findings are that grammatically metaphorical representations of meanings form a "thingy" discourse, in which events become things, and participants and actors in processes are usually reduced to circumstances. Additionally, established patterns of metonymic transfer tend to hide human participants and actors. Also, as the examples presented in the paper show, more than one figure is usually present in a single clause. The analysis of the variability of the figurative language types shows that the use of a certain type of figure depends on theme, not exclusively on the genre.

The research concludes that identified figurative language in analyzed textbooks supports an idea of (historical) determinism and representation of a world in which there are no real actors of (social) historical events and processes. Simultaneously, events and processes are represented as things or states, which develops a picture of reality with a determined state of affairs. This forms a gap between students and the reality represented in textbooks, while disabling empathy and the ability to form active relations to the events from our past.

Key words: textbook language, history textbooks, figurative language, grammatical metaphor, patterns of metonymic transfer. 